\title{
Refrigeração e cera na conservação pós-colheita da tangerina IAC 2019Maria
}

Julia Claudiane da Veiga ${ }^{1}$, Mariane Aparecida Barbará ${ }^{1}$, Bárbara Marçon Pereira da Silva ${ }^{1}$, Sílvia Regina de Toledo Valentini ${ }^{2}$, Mariângela Cristofani-Yaly ${ }^{3} \&$ Ilana Urbano Bron ${ }^{2}$

\section{RESUMO}

A tangerina brasileira IAC 2019Maria é uma alternativa promissora para um mercado desprovido de opções. Objtevou-se com esse trabalho avaliar o potencial da refrigeração e da associação desta com o recobrimento à base de cera na conservação pós-colheita da tangerina IAC 2019Maria. No primeiro experimento, frutos foram armazenados a 24,10 e $5{ }^{\circ} \mathrm{C}$ por 18 dias, seguidos de transferência para $24^{\circ} \mathrm{C}$ por mais 18 dias. No segundo experimento, frutos sem e com aplicação de cera à base de carnaúba $(12 \%)$ foram armazenados a 24 e $5{ }^{\circ} \mathrm{C}$ por 18 dias, seguidos de transferência para $24{ }^{\circ} \mathrm{C}$ por mais 18 dias. Frutos armazenados a 5 e $10{ }^{\circ} \mathrm{C}$ mantiveram a firmeza com menor perda de massa, quando comparados aos frutos armazenados a $24{ }^{\circ} \mathrm{C}$. Frutos refrigerados também apresentaram menor incidência de podridões e manutenção da aparência durante a comercialização simulada, especialmente aqueles anteriormente mantidos a $5{ }^{\circ} \mathrm{C}$. A aplicação da cera diminuiu a perda de massa e firmeza em frutos mantidos constantemente a $24^{\circ} \mathrm{C}$. Também naqueles anteriormente refrigerados a $5^{\circ} \mathrm{C}$, a aplicação da cera foi responsável pela menor perda de firmeza e massa, com menor incidência de podridões. A utilização de cera não interferiu nos atributos sensoriais da tangerina. Conclui-se que a refrigeração a 5 e $10{ }^{\circ} \mathrm{C}$ por 18 dias é eficiente para a conservação da tangerina IAC 2019Maria e que há efeito aditivo da cera à base de carnaúba $(12 \%)$ na conservação de frutos previamente refrigerados a $5{ }^{\circ} \mathrm{C}$.

Termos de indexação: Citrus reticulata, Citrus sinensis, citros, qualidade.

\section{Refrigeration and wax on postharvest conservation of IAC 2019Maria tangerines}

\section{SUMMARY}

IAC 2019Maria tangerine is a promising alternative to deal with Brazilian market lack of options. The objective of this study was to evaluate the potential use of refrigeration associated, or not, with a carnauba-based wax coating on the post-harvest conservation of IAC 2019Maria. In the first experiment, fruit were stored at 24,10 and $5{ }^{\circ} \mathrm{C}$ for 18 days, followed by transfer to $24{ }^{\circ} \mathrm{C}$ for more 18 days. In the second experiment, fruit with and without application of carnauba-based wax $(12 \%)$ were stored at 5 and $24^{\circ} \mathrm{C}$ for 18 days, followed by transfer to $24{ }^{\circ} \mathrm{C}$ for more 18 days. The quality analyses were soluble solids, titratable acidity, ascorbic acid content, mass loss, pulp

\footnotetext{
${ }^{1}$ Programa de Pós-graduação em Agricultura Tropical e Subtropical, Instituto Agronômico - IAC, Campinas, SP, Brasil

${ }^{2}$ Centro de Ecofisiologia e Biofísica, Instituto Agronômico - IAC, Campinas, SP, Brasil

${ }^{3}$ Centro de Citricultura, Instituto Agronômico - IAC, Campinas, SP, Brasil

Autor correspondente: Ilana Urbano Bron, Instituto Agronômico - IAC, Av. Dr. Theodureto de Almeida Camargo, 1500, CEP 13075-630, Campinas, SP, Brasil. E-mail: ilana@iac.sp.gov.br
} 
firmness, skin color, disease incidence and sensory attributes. Fruit stored at 5 and $10{ }^{\circ} \mathrm{C}$ maintained firmness with a lower mass loss, when compared to fruit stored at $24^{\circ} \mathrm{C}$. Refrigerated fruit had also a lower disease incidence and better appearance during marketing simulation, especially those previously kept at $5{ }^{\circ} \mathrm{C}$. Wax application diminished mass and firmness loss in fruit maintained constantly at $24^{\circ} \mathrm{C}$. Also, in those fruit previously refrigerated at $5{ }^{\circ} \mathrm{C}$, wax application was responsible for lower mass and firmness loss, with lower disease incidence. The use of wax did not interfere with the tangerine sensory attributes. In conclusion, the refrigeration at 5 and $10{ }^{\circ} \mathrm{C}$ for 18 days is an efficient method for conservation of IAC 2019Maria tangerine and there was an additive effect of carnauba-based wax $(12 \%)$ on preserving pre-refrigerated fruit at $5{ }^{\circ} \mathrm{C}$.

Index terms: Citrus reticulata, Citrus sinensis, citrus, quality.

\section{INTRODUÇÃO}

A produção de tangerinas no estado de São Paulo corresponde a $38 \%$ da produção nacional, sendo que a tangerina Ponkan (Citrus reticulata Blanco) e o tangor Murcott [C. reticulata Blanco x C. sinensis (L.) Osbeck], são responsáveis por mais de $80 \%$ da área plantada, ou seja, um indicativo que comprova o baixo número de variedades cultivadas (IBGE, 2018). O centro de citricultura 'Sylvio Moreira' do Instituto Agronômico de Campinas (IAC) tem pesquisado novas variedades de tangerina com melhores perspectivas de mercado (IEA, 2015). Na busca pela diversificação de um mercado carente de opções, a tangerina IAC 2019Maria, que apresenta características organolépticas promissoras, pode ser uma alternativa para os agricultores. O estudo do comportamento dessa variedade frente às diversas técnicas de conservação existentes é essencial para que possam ser desenvolvidas estratégias pós-colheita eficientes para orientar os produtores e mercadistas.

A refrigeração é a tecnologia mais utilizada na pós-colheita de frutas cítricas in natura, pois com a redução da temperatura ocorre diminuição do metabolismo e, consequentemente, o prolongando a vida pós-colheita do fruto. A definição da correta temperatura de armazenamento para uma determinada variedade é de extrema importância para maximizar a conservação e evitar danos fisiológicos por frio. Segundo Kluge et al. (2006) normalmente, os danos caudados pelo frio em frutas cítricas se caracterizam pelo aparecimento de depressões superficiais necróticas na casca quando submetidas ao armazenamento por um longo período a baixas temperaturas. Segundo Chitarra \& Chitarra (2005), a desordem causada na casca dos frutos é prejudicial, acarretando depreciação do produto diante do consumidor. As tangerinas geralmente são armazenadas à temperatura de $5-8^{\circ} \mathrm{C}$ (Obenland et al., 2013).

Uma técnica comumente utilizada associada à refrigeração é a aplicação de cera, que proporciona uma barreira às trocas gasosas e água, melhorando a qualidade da fruta e aumentando o período de comercialização (Valencia-Chamorro et al., 2010). A aplicação de ceras pode contribuir com o prolongamento da vida pós-colheita uma vez que reduz a perda de massa e, consequentemente, o murchamento do fruto. O uso da cera, no entanto, pode ocasionar fermentação em alguns frutos, o que altera o sabor e, consequentemente, diminui a qualidade do fruto.

Frutos de laranjeira 'Folha Murcha' armazenados a $7{ }^{\circ} \mathrm{C}$ apresentaram menor perda de massa (Todisco et al., 2012). A manutenção do sabor em tangerinas foi relatada por Tietel et al. (2012) em tangerinas 'Or' e 'Odem' armazenadas em temperaturas de $2^{\circ} \mathrm{C}$ a $8^{\circ} \mathrm{C}$. A aplicação de recobrimento à base de carnaúba prolonga a vida pós-colheita da laranja cv. Valência Delta armazenada a $24{ }^{\circ} \mathrm{C}$ proporcionando menor perda de massa e brilho dos frutos (Pereira et al., 2014). Segundo Hassan et al. (2014) o armazenamento a $5{ }^{\circ} \mathrm{C}$ combinado com a aplicação de cera de abelha (12\%) foi eficaz na manutenção da qualidade de tangerinas var. Siam Banjar, diminuindo a perda de massa e a incidência de podridões, além de maior aceitabilidade sensorial.

Assim, o conhecimento das alterações físico-químicas que ocorrem na tangerina IAC 2019Maria durante a pós-colheita quando armazenadas a temperaturas baixas e submetidas à aplicação de cera, podem permitir a adaptação ou a criação de tecnologias para retardar a senescência e manter a qualidade dessa tangerina. Com isso, objetivou-se com esse trabalho avaliar o potencial do uso da refrigeração e do recobrimento com cera na conservação pós-colheita da tangerina IAC 2019Maria.

\section{MATERIAL E MÉTODOS}

Foram realizados dois experimentos; no primeiro, tangerinas IAC 2019Maria foram colhidas durante a safra de 2017, no mês de maio, com a casca completamente amarela. Os frutos foram selecionados visualmente quanto 
à uniformidade do diâmetro e coloração e armazenadas em três temperaturas, $24{ }^{\circ} \mathrm{C} \pm 2 / 70 \% \mathrm{UR}, 10^{\circ} \mathrm{C} \pm 2 / 86 \%$ UR e $5{ }^{\circ} \mathrm{C} \pm 2 / 84 \%$ UR, por um período de 18 dias. Frutos que permaneceram a $24{ }^{\circ} \mathrm{C}$ foram avaliados a cada três dias. Ao final dos 18 dias, frutos armazenados a 10 e $5^{\circ} \mathrm{C}$ foram transferidos para temperatura de $24^{\circ} \mathrm{C} \pm 2 / 70 \% \mathrm{UR}$ para simular um período de comercialização. Durante o período de refrigeração as análises foram realizadas a cada seis dias e, após a transferência, realizadas em intervalos de três dias. $\mathrm{O}$ delineamento experimental foi inteiramente casualizado em esquema fatorial duplo (temperatura $\mathrm{x}$ tempo de armazenamento).

No segundo experimento, tangerinas IAC 2019Maria foram colhidas no mês de junho, durante a safra de 2017 com a casca completamente amarela. Depois de selecionados quanto à uniformidade do diâmetro e coloração, os frutos foram lavados com água e secos por ventilação natural. Em seguida, metade dos frutos recebeu aplicação manual de três gotas de cera a base de carnaúba (12\%). Frutos encerados e não encerados foram armazenados a $24{ }^{\circ} \mathrm{C}$ $\pm 2 / 70 \%$ UR e $5{ }^{\circ} \mathrm{C} \pm 2 / 84 \%$ por 18 dias. Ao final dos 18 dias, frutos armazenados a $5{ }^{\circ} \mathrm{C}$ foram transferidos para temperatura de $24{ }^{\circ} \mathrm{C} \pm 2 / 70 \%$ UR por mais 18 dias para simular um período de comercialização. As análises foram efetuadas a cada três dias quando os frutos estavam a $24^{\circ} \mathrm{C}$ e a cada seis dias quando refrigerados. $\mathrm{O}$ delineamento experimental foi inteiramente casualizado em esquema fatorial triplo (temperatura $\mathrm{x}$ aplicação de cera $\mathrm{x}$ tempo de armazenamento).

Em ambos os experimentos as análises realizadas foram: sólidos solúveis, acidez titulável, ácido ascórbico (cinco repetições compostas por 2 frutos), perda de massa (sete repetições de 1 fruto), firmeza (dez repetições de 1 fruto), incidência de podridões (cinco repetições de 20 frutos), aparência e sabor (trinta provadores). O teor de sólidos solúveis no suco foi determinado com refratômetro digital (Atago PR-101, Japão) e o resultado expresso em ${ }^{\circ}$ Brix. A acidez titulável foi determinada por titulometria e expressa em g de ácido cítrico/100 mL de amostra. $\mathrm{O}$ ácido ascórbico foi determinado por titulometria com 2,6 diclorofenol indofenol (DCFI) até coloração rosada persistente por 15 segundos e expresso em mg de ácido ascórbico/100 g de polpa (Carvalho et al., 1990).

A perda de massa foi determinada por meio da pesagem dos frutos em balança semi-analítica, com cálculo da diferença entre o peso final e inicial, e os resultados expressos em porcentagem (\%). A firmeza dos frutos foi avaliada com texturômetro (TA-XT2i - Texture Analyser, Stable Micro Systems), com probe cilíndrico com diâmetro de $35 \mathrm{~mm}$, velocidade pré-teste e pós-teste de $2 \mathrm{~mm} / \mathrm{s}$ e taxa de compressão de $9 \mathrm{~mm}$ e os resultados expressos em Newtons (N). A cor da casca foi determinada com colorímetro (Minolta CR-300), tomando-se duas leituras por fruto, em lados opostos da sua região equatorial. O sistema de leitura utilizado foi o CIELAB e os resultados foram expressos em ângulo Hue $\left({ }^{\circ} \mathrm{H}\right)$.

A incidência de podridões foi avaliada pela contagem do número de frutos apresentando sintomas de podridões e expressa em porcentagem (\%). A avaliação da aparência externa e sabor fruto, foi realizada por análise sensorial com 30 provadores não treinados, por meio de escala hedônica de 5 pontos (Moraes, 1988) - Muito Bom (nota 5); Bom (nota 4); Regular (nota 3); Ruim (nota 2) e Muito Ruim (nota 1). As frutas foram lavadas e higienizadas, descascadas e separadas por gomos. Cada amostra recebeu uma codificação de três dígitos. As amostras foram entregues para os participantes juntamente com um questionário para atribuição das notas. Para a avaliação da aparência, um fruto representativo do lote foi apresentado para os provadores.

Os dados obtidos foram submetidos à analise de variância (ANOVA) e a comparação de média foi realizada pelo teste de Tukey $5 \%(\mathrm{p}<0,05)$, utilizando o programa Assistat (Silva \& Azevedo, 2016). Para análise dos dados de incidência de podridões, foi realizada análise não paramétrica de múltiplas proporções, por meio do programa $\mathrm{R}(5 \%)$.

\section{RESULTADOS}

As três temperaturas de armazenamento não interferiram nas características físico-químicas dos frutos, como teor de sólidos solúveis, apresentando média de $11^{\circ} \mathrm{Brix}$, acidez titulável com média de $0,9 \mathrm{~g}$ de ácido cítrico $100 \mathrm{~mL}$ de amostra e ácido ascórbico ${ }^{-1}$, com média de $31 \mathrm{mg}$ de ácido ascórbico $100 \mathrm{~mL}$ de amostra ${ }^{-1}$.

A refrigeração contribuiu para menor perda de massa das tangerinas; frutos armazenados a $24^{\circ} \mathrm{C}$ apresentaram maior perda de massa quando comparados com os frutos armazenados a 10 e $5^{\circ} \mathrm{C}(\mathrm{p}<0,05)$ durante todo o período estudado. A partir do $12^{\circ}$ dia de armazenamento, quando comparam-se as duas temperaturas de refrigeração, verificou-se que os frutos armazenados a $10^{\circ} \mathrm{C}$ perderam menos massa que aqueles que permaneceram a $5{ }^{\circ} \mathrm{C}$. Aos 12 dias de armazenamento a perda de massa foi de $8 \%$ para os frutos mantidos a $24{ }^{\circ} \mathrm{C}, 2,5 \%$ para os frutos mantidos a $10{ }^{\circ} \mathrm{C}$ e de $3 \%$ para os frutos armazenados 
a $5{ }^{\circ} \mathrm{C}(\mathrm{p}<0,05)$ (Figura 1A). Durante o período de transferência, os frutos anteriormente armazenados a $10^{\circ} \mathrm{C}$ apresentaram menor perda de massa quando comparados aos frutos armazenados a $5^{\circ} \mathrm{C}$, assumindo valores médios de 8,8 e 10,1\%, respectivamente $(\mathrm{p}<0,05)$ (Figura 1A).

A temperatura influenciou significativamente a firmeza da polpa; frutos armazenados a $5{ }^{\circ} \mathrm{C}$ permaneceram com firmeza maior durante todo o período pós-colheita. Os valores médios encontrados, considerando todo o período de avaliação, foram de $94,8 \mathrm{~N}, 104,1 \mathrm{~N}$ e $113,1 \mathrm{~N}$, para os frutos armazenados a 24,10 e $5^{\circ} \mathrm{C}$, respectivamente $(\mathrm{p}<0,05)$. Independentemente da temperatura, houve perda de firmeza dos frutos ao longo do armazenamento, principalmente a partir do $12^{\circ}$ dia (Figura 1B). Ao longo do

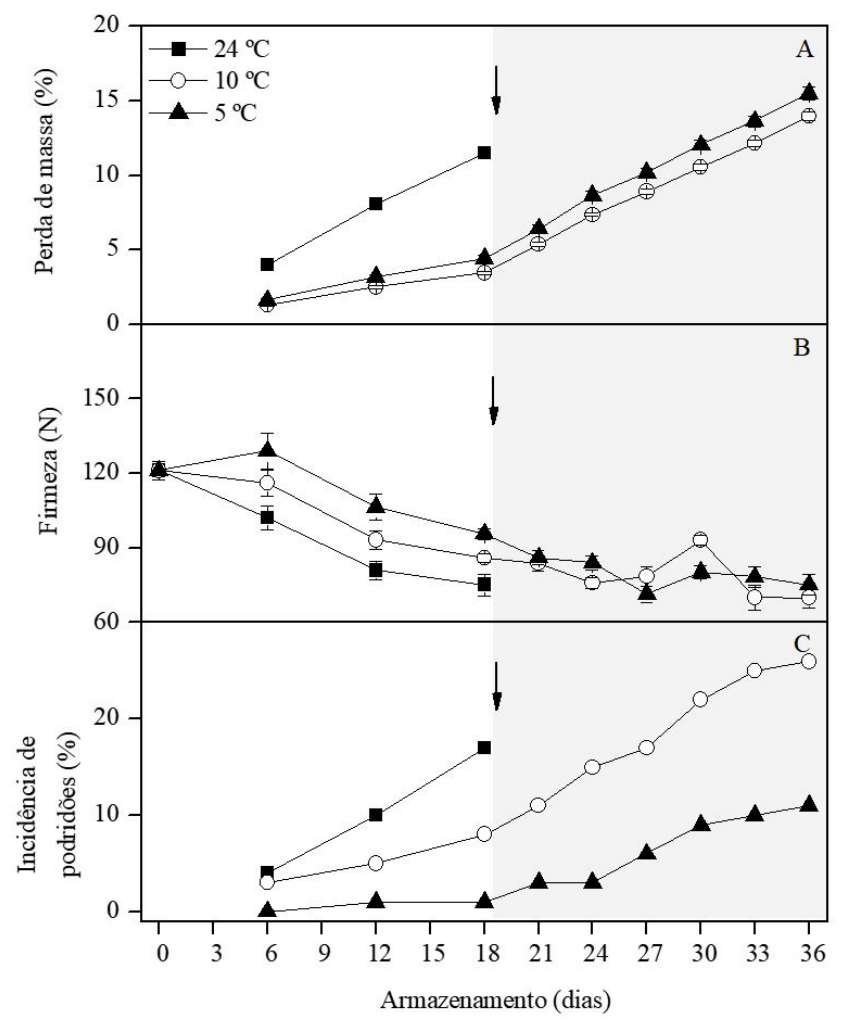

Figura 1. Perda de massa (\%) (A); Firmeza (N) (B); Incidência de podridões $(\%)(C)$ em tangerinas IAC 2019Maria armazenadas a $24{ }^{\circ} \mathrm{C} \pm 2 / 70 \%$ UR, $10{ }^{\circ} \mathrm{C} \pm 2 / 86 \%$ UR e $5{ }^{\circ} \mathrm{C} \pm 2 / 84 \%$ UR por 18 dias, seguido de transferência para $24^{\circ} \mathrm{C}$ por mais 18 dias. A seta indica o momento exato em que os frutos refrigerados $\left(10\right.$ e $\left.5^{\circ} \mathrm{C}\right)$ foram transferidos para $24^{\circ} \mathrm{C}$. A área sombreada representa o período que os frutos, previamente refrigerados, permaneceram a $24^{\circ} \mathrm{C}$. Barras verticais indicam o erro padrão das médias (A $n=7 ; B$ n=10; $\mathrm{C} n=100$ ). período de transferência não houve diferença significativa entre os frutos armazenados nas diferentes temperaturas.

Houve diferença nas incidências de podridões (Penicillium digitatum, Penicillium italicum e Colletotrichum spp) dos frutos armazenados nas três temperaturas $(\mathrm{p}<0,05)$. $\mathrm{O}$ armazenamento refrigerado $\left(10\right.$ e $\left.5^{\circ} \mathrm{C}\right)$ contribuiu para menor incidência de podridões nas tangerinas IAC 2019Maria. Os frutos mantidos a $24{ }^{\circ} \mathrm{C}$ apresentaram a maior porcentagem de incidência, $17 \%$ ao final dos 18 dias de armazenamento. Os frutos mantidos a $10{ }^{\circ} \mathrm{C}$ tiveram uma incidência de $8 \%$, enquanto aqueles armazenados a $5{ }^{\circ} \mathrm{C}$, os sintomas de podridões apareciam em $1 \%$ dos frutos (Figura 1C). Após a transferência, os frutos que haviam sido armazenados $\mathrm{a} 10^{\circ} \mathrm{C}$ apresentaram, durante a comercialização, maior incidência quando comparados aos mantidos a $5{ }^{\circ} \mathrm{C}(\mathrm{p}<0,05)$. Ao final do armazenamento, a incidência era de $26 \%$ e $11 \%$ para os frutos mantidos a 10 e $5{ }^{\circ} \mathrm{C}$, respectivamente (Figura $1 \mathrm{C}$ ).

$\mathrm{Na}$ análise sensorial avaliaram-se a aparência e o sabor das tangerinas IAC 2019Maria. Os frutos mantidos a $24{ }^{\circ} \mathrm{C}$ receberam nota 4 (bom) de aparência até os 12 dias, enquanto, os frutos armazenados sob refrigeração mantiveram nota 4 até o final dos 18 dias de armazenamento (Figura 2A). Frutos anteriormente mantidos a $10{ }^{\circ} \mathrm{C}$ apresentaram um decréscimo das notas ao longo do armazenamento $(\mathrm{p}<0,05)$. Durante o período de transferência, os frutos mantidos a $5{ }^{\circ} \mathrm{C}$ não apresentaram diferença significativa e permaneceram com notas de aparência superiores a $3(\mathrm{p} \geq 0,05)$ (Figura 2A).

Para o atributo sabor, não houve influência da temperatura de armazenamento, nem tão pouco do tempo de armazenamento. Quando considerado todo o período de avaliação, a média de notas foi de 3,8, 3,9 e 3,6 para os frutos armazenados a 24,10 e $5^{\circ} \mathrm{C}$, respectivamente $(p \geq 0,05)$ (Figura 2B). Mesmo após o período de transferência não houve diferença significativa. Ao longo do período de transferência foi possível observar decréscimo na média das notas, sendo que no ínicio da transferência (18 dias) a média das notas era de 3,7 e ao final (36 dias) era de $2,9(\mathrm{p}<0,05)$ (Figura 2B).

No experimento 2, no qual avaliou-se $\mathrm{o}$ armazenamento da tangerina IAC 2019Maria nas temperaturas de 24 e $5{ }^{\circ} \mathrm{C}$ sem e com aplicação de cera, a perda de massa dos frutos mantidos a $24^{\circ} \mathrm{C}$ sem cera foi maior quando comparada àquela dos frutos com aplicação de cera $(\mathrm{p}<0,05)$. Aos 18 dias de armazenamento a perda de massa dos frutos mantidos a $24{ }^{\circ} \mathrm{C}$ era de 11 e $8,1 \%$ para os frutos sem e com aplicação de cera. Para os frutos mantidos a $5{ }^{\circ} \mathrm{C}$ não houve efeito significativo da aplicação de cera 


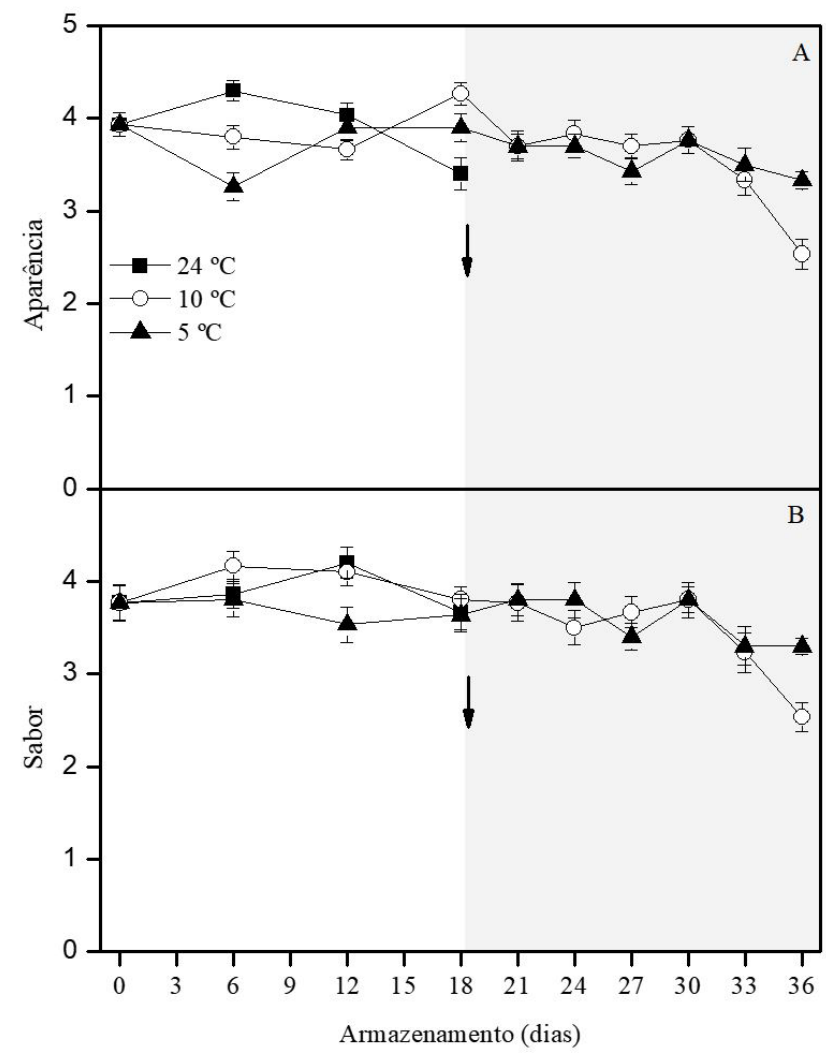

Figura 2. Aparência (A); Sabor (B) de tangerinas IAC 2019Maria armazenadas a $24^{\circ} \mathrm{C} \pm 2 / 70 \% \mathrm{UR}, 10^{\circ} \mathrm{C} \pm 2 / 86 \%$ UR e $5{ }^{\circ} \mathrm{C} \pm 2 / 84 \%$ UR por 18 dias, seguido de transferência para $24{ }^{\circ} \mathrm{C}$ por mais 18 dias. A seta indica o momento exato em que os frutos refrigerados $\left(10\right.$ e $\left.5{ }^{\circ} \mathrm{C}\right)$ foram transferidos para $24^{\circ} \mathrm{C}$. A área sombreada representa o período em que os frutos, previamente refrigerados, permaneceram a $24{ }^{\circ} \mathrm{C}$. Barras verticais representam o erro padrão das médias $(\mathrm{n}=30)$.

até os 12 dias de armazenamento $(\mathrm{p} \geq 0,05)$. Aos 18 dias de armazenamento, frutos a $5{ }^{\circ} \mathrm{C}$ apresentaram perda de massa de $2,9 \%$ e $1,9 \%$ para os frutos sem e com a aplicação de cera, respectivamente $(\mathrm{p}<0,05)$ (Figura 3A). Após o período de refrigeração $\left(5^{\circ} \mathrm{C}\right)$ os frutos sem aplicação de cera apresentaram maior perda de massa quando comparado com os frutos tratados $(\mathrm{p}<0,05)$ (Figura 3A).

Quando consideramos todo o período de armazenamento, verificou-se que a aplicação de recobrimento contribuiu para redução de perda de firmeza dos frutos $(\mathrm{p}<0,05)$, independentemente da temperatura de armazenamento. Os valores médios encontrados foram de $64,3 \mathrm{~N}$ para os frutos sem aplicação de cera e $67,4 \mathrm{~N}$ para os frutos que receberam a aplicação de recobrimento $(\mathrm{p}<0,05)$. Enquanto frutos armazenados a $24{ }^{\circ} \mathrm{C}$ apresentavam

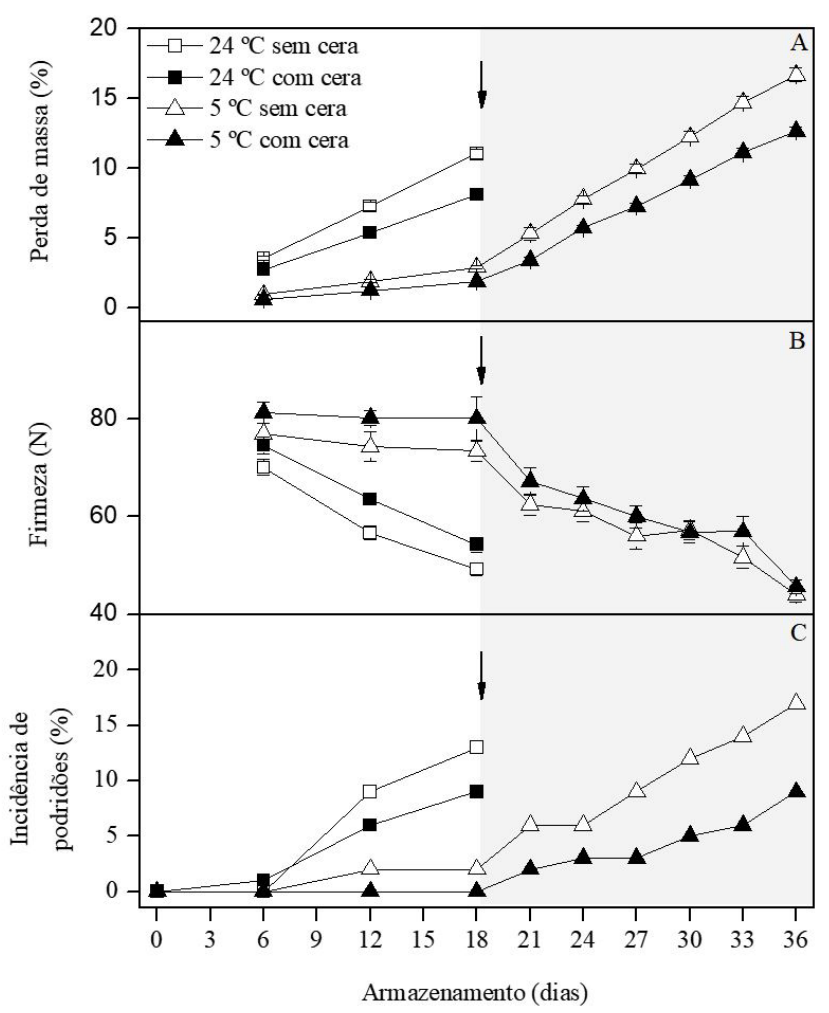

Figura 3. Perda de massa (\%) (A); Firmeza (N) (B); Incidência de podridões (\%) (C) em tangerinas IAC 2019Maria armazenadas a $24^{\circ} \mathrm{C} \pm 2 / 70 \% \mathrm{UR}$, e $5{ }^{\circ} \mathrm{C} \pm 2 / 84 \%$ sem e com cera por 18 dias, seguido de transferência para $24^{\circ} \mathrm{C}$ por mais 18 dias. A seta indica o momento exato em que os frutos refrigerados $\left(10\right.$ e $\left.5^{\circ} \mathrm{C}\right)$ foram transferidos para $24^{\circ} \mathrm{C}$. A área sombreada representa o período em que os frutos, previamente refrigerados, permaneceram a $24{ }^{\circ} \mathrm{C}$. Barras verticais representam o erro padrão das médias ( $\mathrm{A} n=7 ; \mathrm{B} n=10 ; \mathrm{C} n=100$ ).

firmeza média de 54,4 N, aqueles armazenados sob refrigeração apresentavam 77,3 N (Figura 3B). Quando os frutos saíram da refrigeração, os que não receberam aplicação de cera apresentaram, no período da simulação comercial, menor firmeza com valor médio de $58,1 \mathrm{~N}$, quando comparados com os frutos tratados com 61,5 $\mathrm{N}(\mathrm{p}<0,05)$. Independentemente do tratamento, houve perda de firmeza dos frutos ao longo do armazenamento (Figura 3B).

Tangerinas IAC 2019Maria mantidas a $5{ }^{\circ} \mathrm{C}$ com aplicação de cera não apresentaram sintomas de podridão. Apesar dos frutos não tratados armazenados a $24{ }^{\circ} \mathrm{C}$ terem apresentado maior incidência durante todo o período de avaliação, essa diferença não foi significativa quando comparado com os frutos com 
cera $(p \geq 0,05)$. Aos 18 dias de armazenamento, os frutos mantidos a $24{ }^{\circ} \mathrm{C}$ apresentaram incidência de 13 e $9 \%$ para os frutos sem aplicação de cera e com cera, respectivamente. Para os frutos mantidos a $5{ }^{\circ} \mathrm{C}$ a incidência foi de $1 \%$ nos frutos sem aplicação de cera, significativamente menor quando comparado com os demais tratamentos $(\mathrm{p}<0,05)$ (Figura 3C). A incidência de podridões durante o período de transferência foi maior nos frutos não tratados com a cera, quando comparado com os frutos com aplicação de cera. Os frutos armazenados sem aplicação de cera apresentaram incidência de $17 \%$ ao final do período de avaliação, enquanto que nos frutos com cera a incidência foi $9 \%(\mathrm{p}<0,05)$ (Figura 3C).

$\mathrm{Na}$ análise sensorial foram avaliados os atributos aparência e sabor. A utilização de recobrimento não influenciou a avaliação da aparência dos frutos de tangerina IAC 2019Maria. Os frutos mantidos a $24{ }^{\circ} \mathrm{C}$, independentemente da aplicação de cera, receberam as menores notas a partir do $12^{\circ}$ dia de armazenamento $(\mathrm{p}<0,05)$. Aos 12 dias, os frutos mantidos a $24{ }^{\circ} \mathrm{C}$ receberam notas abaixo de 4 , sendo essa atribuída aos frutos que são considerados bons. Quando considerado todo o período de armazenamento, houve decréscimo nas notas ao longo do tempo, independentemente da temperatura de armazenamento (Figura 4A). A aplicação da cera não influenciou a aparência dos frutos durante a comercialização simulada pós-refrigeração. A média de notas durante todo o período de avaliação foi de 3,5, independentemente da aplicação de cera. Ao longo do armazenamento houve redução das notas $(\mathrm{p}<0,05)$ (Figura 4A).

Não houve diferença significativa no sabor dos frutos armazenados nas diferentes temperaturas e com ou sem aplicação de cera $(p \geq 0,05)$. Quando considerado todo o período pós-colheita, houve diminuição das notas quando comparados os frutos no dia da colheita com o último dia de armazenamento $(\mathrm{p}<0,05)$. Os frutos receberam notas com média 4,5 no dia da colheita e ao final do período de armazenamento a nota média atribuída aos frutos foi de 3,6 ( $<<0,05)$ (Figura 4B). Frutos durante a transferência não apresentaram diferença no sabor entre os tratamentos, a média das notas atribuída pelos provadores foi 6,6 e 6,5 para os frutos sem tratamento e para os frutos com aplicação de cera, respectivamente $(\mathrm{p} \geq 0,05)$. Ao longo do armazenamento a média de notas se manteve desde o dia da transferência (18 dias) até o final do período de avaliação (36 dias) (Figura 4B).

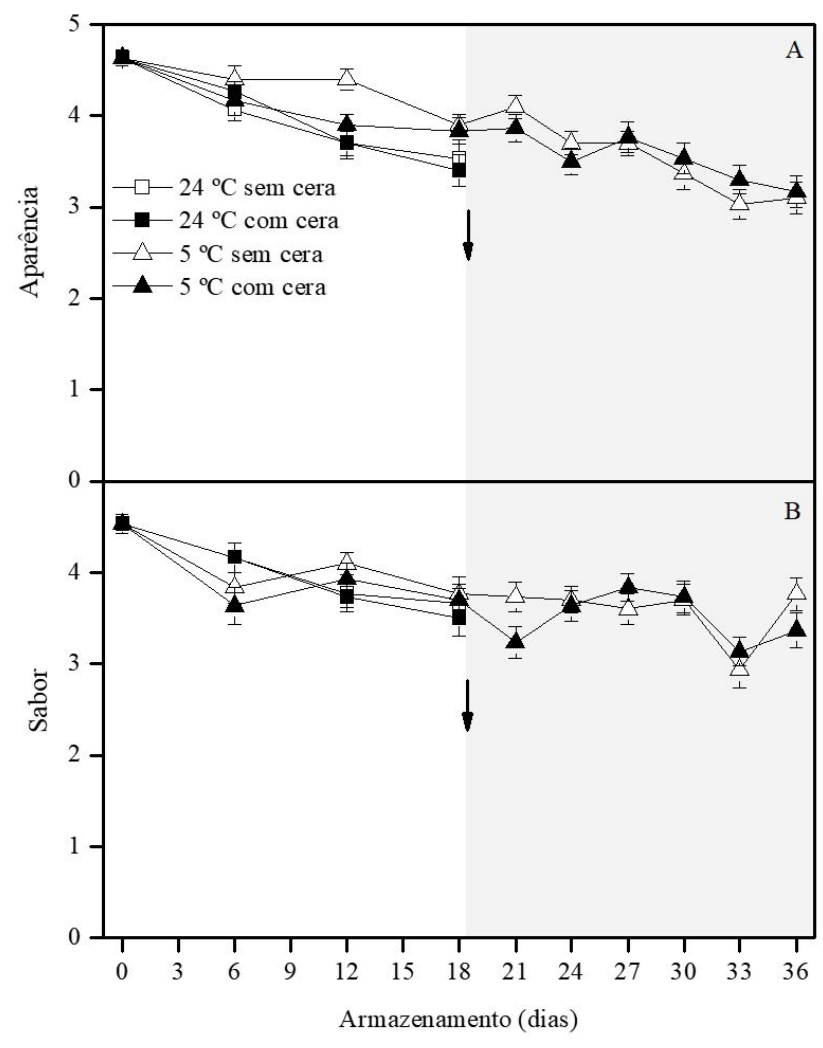

Figura 4. Aparência (A); Sabor (B) de tangerinas IAC 2019Maria armazenadas a $24{ }^{\circ} \mathrm{C} \pm 2 / 70 \%$ UR, e $5{ }^{\circ} \mathrm{C} \pm 2 / 84 \%$ UR sem e com cera por 18 dias, seguido de transferência para $24^{\circ} \mathrm{C}$ por mais 18 dias. A seta indica o momento exato que os frutos refrigerados $\left(10\right.$ e $\left.5^{\circ} \mathrm{C}\right)$ foram transferidos para $24^{\circ} \mathrm{C}$. A área sombreada representa o período em que os frutos, previamente refrigerados, permaneceram a $24{ }^{\circ} \mathrm{C}$. Barras verticais representam o erro padrão das médias $(\mathrm{n}=30)$.

\section{DISCUSSÃO}

Para a manutenção da qualidade e prolongamento da conservação dos frutos é necessário a utilização de métodos de conservação. A refrigeração é o método mais utilizado para manter a qualidade dos produtos hortícolas frescos após a colheita, pois contribui para a diminuição da perda de água, crescimento de patógenos além de retardar a senescência. A temperatura de armazenamento segura para tangerinas é de $5-8^{\circ} \mathrm{C}$ (Obenland et al., 2013). A utilização da refrigeração durante o armazenamento apesar de reduzir a incidência de podridões, pode ocasionar distúrbios fisiológicos (Brackmann et al., 2008). As frutas cítricas demonstram sensibilidade a temperaturas baixas, acarretando na morte das células da casca, formação 
de manchas circulares deprimidas, caracterizado por depressões superficiais necróticas de coloração marrom e com alterações no sabor dos frutos (Sala, 1998; Porat et al., 2004; Kluge et al., 2006).

Nas condições deste estudo a qualidade da tangerina IAC 2019Maria não foi prejudicada pelo armazenamento refrigerado, ou seja, não foi observado nenhum desses sintomas nas condições estudadas.

A refrigeração contribuiu para redução da perda de massa e firmeza. A média de perda de massa dos frutos armazenados a $24{ }^{\circ} \mathrm{C}$ foi $7,9 \%$, já os frutos mantidos a $5{ }^{\circ} \mathrm{C}$ e $10^{\circ} \mathrm{C}$ perderam em média 3,1 e $2,4 \%$ de massa, respectivamente (Figura 1A). Destaca-se que houve maior perda de massa nos frutos mantidos a $5^{\circ} \mathrm{C}$, quando comparados com aqueles mantidos a $10^{\circ} \mathrm{C}$, a partir dos 12 dias de armazenamento. Quanto maior a diferença de pressão de vapor entre o produto e a atmosfera externa, maior será a perda de água por ele. A umidade relativa no ambiente em que os frutos estavam armazenados a $5{ }^{\circ} \mathrm{C}$ encontrava-se mais baixa, $84 \%$, enquanto que os frutos mantidos a $10{ }^{\circ} \mathrm{C}$ estavam sob umidade de $86 \%$, o que pode ter levado a essa diferença de perda de massa. A perda de massa é um atributo importante que reduz a qualidade dos frutos (Bajwa \& Anjum, 2007). Quando superior a $6 \%$ pode tornar o fruto inadequado para a comercialização por causar perceptível depreciação na aparência dos frutos cítricos, com visível enrugamento e desidratação da casca (Pereira et al., 2014). Aos 12 dias de armazenamento, os frutos a $24^{\circ} \mathrm{C}$ já apresentavam perda de massa de $8 \%$, enquanto que os frutos sob 10 e $5{ }^{\circ} \mathrm{C}$ apresentavam uma perda de $2,5 \%$ e $3,2 \%$, respectivamente (Figura 1A).

Em concordância com o resultado da perda de massa, também foi verificado pelos provadores, durante a análise sensorial, melhor aparência dos frutos mantidos sob refrigeração (Figura 2A). A refrigeração, portanto, prolongou a vida pós-colheita do fruto e manteve boa aparência até o final do armazenamento, sem diminuição das notas.

Frutos armazenados a $5{ }^{\circ} \mathrm{C}$ apresentaram maior firmeza da polpa. A redução da temperatura diminui o metabolismo dos frutos e reações tais como a decomposição de pectinas da parede celular. Além disso, a temperatura de armazenamento também influencia na transpiração, quanto maior for a temperatura em que os frutos estão armazenados, maiores são as perdas por transpiração. A transpiração resulta em perda de massa e turgescência do fruto, refletindo em perda de firmeza dos frutos.
A temperatura de refrigeração contribuiu para menor incidência de podridões, sendo que a temperatura de $5{ }^{\circ} \mathrm{C}$ foi mais eficiente em controlar o aparecimento de sintomas de podridões (Figura 1C). As condições de armazenamento afetaram o crescimento de patógenos importantes na pós-colheita dos citros como o Penicillium digitatum e Penicillium italicum, apresentando um efeito fungistático, ou seja, inibindo o desenvolvimento dos patógenos. A faixa ideal para o desenvolvimento desses patógenos é a $24^{\circ} \mathrm{C}$ e muito lentamente em temperaturas acima de $30^{\circ} \mathrm{C}$ e abaixo de $10^{\circ} \mathrm{C}$ (Bassanez et al., 2016). Segundo Plaza et al. (2003), o P. digitatum é capaz de germinar e crescer na faixa de 4 a $30{ }^{\circ} \mathrm{C}$. A temperatura ideal de desenvolvimento é $25^{\circ} \mathrm{C}$ e com um ciclo de vida curto, de 3 a 5 dias (Sukorini et al., 2013). Durante a refrigeração houve o desenvolvimento do $P$. italicum. Em temperaturas mais baixas o $P$. italicum se desenvolve melhor que o P. digitatum (Bassanez et al., 2016).

Outros métodos de conservação podem ser utilizados em conjunto com a refrigeração, com o intuito de aumentar a vida pós-colheita dos frutos, visando à manutenção da qualidade de maneira mais efetiva. Uma dessas alternativas é a aplicação de cera. Nas condições desse experimento, a aplicação de cera não influenciou o teor de sólidos solúveis, acidez titulável e ácido ascórbico.

A atmosfera modificada, proporcionada pela cera na casca dos frutos, aumenta a concentração de $\mathrm{CO}_{2}$ e reduz os níveis de $\mathrm{O}_{2}$. A alteração no balanço desses gases pode acarretar no aparecimento de sabores desagradáveis e off-flavor, sendo esse fator determinante na escolha da aplicação de recobrimentos. A aplicação de cera nas condições experimentais não trouxe prejuízos para o sabor dos frutos de tangerina IAC 2019Maria (Figura 4B).

Os revestimentos com cera criam uma barreira protetora que possui essencialmente propriedades esperadas: melhora de aparência (brilho), redução de perda de massa, retardo da senescência e, com muita frequência, controle de incidência de podridões pela adição de fungicidas compatíveis com a cera (Parra et al., 2014).

$\mathrm{O}$ efeito da cera em tornar o fruto mais brilhante e consequentemente mais atrativo para o consumidor, não foi observado nas condições experimentais, pois não houve preferência significativa para os frutos com aplicação de cera pelos provadores (Figura 4A).

A cera contribuiu para a redução de perda de massa dos frutos armazenados a $24{ }^{\circ} \mathrm{C}$ e também durante a comercialização simulada dos frutos anteriormente armazenados sob refrigeração $\left(5^{\circ} \mathrm{C}\right)$ (Figura $\left.3 \mathrm{~A}\right)$. Além 
disso, como a perda de massa se dá principalmente pelo processo de transpiração, através da cutícula, a cera cobre essas estruturas dificultando o processo de transpiração.

Outra ação importante da aplicação de cera foi na perda de firmeza dos frutos (Figura 3B). Segundo Li et al. (2018), a diminuição do metabolismo das frutas, promovido pela cera, minimiza a perda de massa e firmeza. Também, com a redução da transpiração e consequentemente menor perda de água pelos frutos, a perda de turgor das células diminui o que contribui para a manutenção da firmeza.

A incidência de podridão nas tangerinas, durante a comercialização simulada, foi reduzida pela aplicação de cera em frutos anteriormente armazenados a $5^{\circ} \mathrm{C}$ (Figura 3C). A cera aplicada forma uma película protetora, revestindo os possíveis ferimentos da casca utilizados como porta de entrada para os patógenos, como o Penicillium spp. Especificamente para este patógeno, a infecção ocorre somente através de ferimentos ou aberturas naturais onde é possível obter os nutrientes que estimulam a germinação dos esporos, uma vez depositados na superfície do fruto (Fischer et al., 2007). A redução nos sintomas de podridões também pode estar relacionada com a redução da taxa dos processos bioquímicos do amadurecimento e senescência que a cera propiciou pela modificação da atmosfera interna dos frutos. Com esse atraso, o fruto pode manter sua capacidade de produzir compostos biocidas, além dos tecidos estarem mais resistentes aos patógenos. Esses efeitos acarretam na inibição de podridões e atraso de infecções ativas de patógenos quiescentes. Além disso, a diminuição de oxigênio promovida pela cera também contribui para inibição do crescimento de microrganismos (Cia \& Benato et al., 2011; Cia \& Benato, 2006).

\section{CONCLUSÃO}

A refrigeração a 5 e $10{ }^{\circ} \mathrm{C}$ por 18 dias é um método eficiente para a conservação da tangerina IAC 2019Maria, principalmente pela redução na perda de massa, perda de firmeza, incidência de podridões e manutenção da aparência. A temperatura de $5{ }^{\circ} \mathrm{C}$ é mais eficiente no controle de podridões.

A aplicação da cera a base de carnaúba na concentração de $12 \%$, não afeta a qualidade sensorial da tangerina IAC 2019Maria. Houve efeito aditivo da cera na refrigeração, evidenciado pela menor incidência de podridões, perda de massa e de firmeza.

\section{AGRADECIMENTOS}

Os autores agradecem à Yolanda Eugenia Alamo Gabrine Boza pelo auxílio nas análises e coleta de dados. À CAPES pela concessão da bolsa ( $\mathrm{n}^{\circ}$ do processo 1838666).

\section{REFERÊNCIAS}

Bajwa, B. E., \& Anjum, F. M. (2007). Improving storage performance of Citrus reticulata Blanco mandarins by controlling some physiological disorders. International Journal of Food Science \& Technology, 42, 495-501.

Bassanez, R. B., Silva, G. J., Feichtenberger, E., Belasque Junior, J., Behlau, F., \& Wulff, N. A. (2016). Doença de citros. In L. Amorim, J. A. M. Rezende, A. Bergamin Filho \& L. E. A. Camargo. Manual de fitopatologia (5. ed., 810 p.). Ouro Fino: Agronômica Ceres.

Brackmann, A., Peterle, M. E., Pinto, J. A. V., Weber, A., Sautter, C. K., \& Eisermann, A. C. (2008). Temperatura e umidade relativa na qualidade da tangerina" Montenegrina" armazenada. Ciência Rural, 38, 340-344.

Carvalho, C. R. L., Mantovani, D. M. B., Carvalho, P. R. N., \& Moraes, R. M. M. (1990). Análises químicas de alimentos. Campinas: ITAL.

Chitarra, M. I. F., \& Chitarra, A. B. (2005). Pós-colheita de frutos e hortaliças: fisiologia e manuseio (785 p.). Lavras: Ed UFLA.

Cia, P., \& Benato, E. A. (2006). Controle alternativo com atmosferas modificada e controlada. In S. M. A. Oliveira, D. Terão, S. S. F. Dantas \& S. C. C. H. Tavares (Eds.), Frutas, olericolas e ornamentais tropicais (pp. 247-264). Brasília: Embrapa Informação Tecnológica.

Cia, P., Benato, E. A., Toledo Valentini, S. R., Sanches, J., Ponzo, F. S., Flôres, D., \& Terra, M. M. (2011). Atmosfera modificada e refrigeração para conservação pós-colheita de uva 'Niagara Rosada'. Pesquisa Agropecuária Brasileira, 45, 1058-1065.

Fischer, I. H., Toffano, L., Lourenço, S., \& Amorim, L. (2007). Caracterização dos danos pós-colheita em citros procedentes de "packinghouse". Fitopatologia Brasileira, 32, 304-310.

Hassan, Z. H., Lesmayati, S., Qomariah, R., \& Hasbianto, A. (2014). Effects of wax coating applications and storage temperatures on the quality of tangerine citrus (Citrus 
reticulata) var. Siam Banjar. International Food Research Journal, 21, 641.

Instituto Brasileiro de Geografia e Estatística - IBGE. (2018). Produção agrícola municipal. Rio de Janeiro: IBGE. Recuperado em 14 junho de 2018, de http://www.sidra.ibge. gov.br/bda/tabela/protabl.asp?c $=1613 \& \mathrm{z}=\mathrm{p} \& \mathrm{o}=18 \& \mathrm{i}=\mathrm{p}$

Instituto de Economia Agricola - IEA. (2015). Citricultura nota 10: da pesquisa para a mesa (Informativo Centro de Citricultuta). Cordeirópolis: Centro de Citricultura IAC. Edição Especial.

Kluge, R. A., Azevedo, R. A., Jomori, M. L. L., Edagi, F. K., Jacomino, A. P., Gaziola, A. S., \& Del Aguila, J. S. (2006). Efeitos de tratamentos térmicos aplicados sobre frutas cítricas armazenadas sob refrigeração. Ciência Rural, 36, 1388-1396.

Li, X., Zhu, X., Wang, H., Lin, X., Lin, H., \& Chen, W. (2018). Postharvest application of wax controls pineapple fruit ripening and improves fruit quality. Postharvest Biology and Technology, 136, 99-110.

Moraes, M. A. C. (1988). Métodos para avaliação sensorial dos alimentos (6. ed., 93 p.). Campinas: Editora da UNICAMP.

Obenland, D., Collin, S., Sievert, J., \& Arpaia, M. L. (2013). Mandarin flavor and aroma volatile composition are strongly influenced by holding temperature. Postharvest Biology and Technology, 82, 6-14.

Parra, J., Ripoll, G., \& Orihuel-iranzo, B. (2014). Potassium sorbate effects on citrus weight loss and decay control. Postharvest Biology and Technology, 96, 7-13.

Pereira, G. S., Machado, F. L. C., \& Costa, J. M. C. (2014). Aplicação de recobrimento prolonga a qualidade póscolheita de laranja 'Valência Delta' durante armazenamento ambiente. Ciência Agronômica, 45, 520-527.

Plaza, P., Usall, J., Teixidó, N., \& Viñas, I. (2003). Effect of water activity and temperature on germination and growth of Penicillium digitatum, P. italicum and Geotrichum candidum. Journal of Applied Microbiology, 94, 549-554.
Porat, R., Weiss, B., Cohen, L., Daus, A., \& Aharoni, N. (2004). Reduction of postharvest rind disorders in citrus fruit by modified atmosphere packaging. Postharvest Biology and Technology, 33, 35-43.

Sala, J. M. (1998). Involvement of oxidative stress in chilling injury in cold-stored mandarin fruits. Postharvest Biology and Technology, 13, 255-261.

Silva, F. A. S., \& Azevedo, C. A. V. (2016). The Assistat Software Version 7.7 and its use in the analysis of experimental data. African Journal of Agricultural Research, 11, 3733-3740.

Sukorini, H., Sangchote, S., \& Khewkhom, N. (2013). Control of postharvest green mold of citrus fruit with yeasts, medicinal plants, and their combination. Postharvest Biology and Technology, 79, 24-31.

Tietel, Z., Lewinsohn, E., Fallik, E., \& Porat, R. (2012). Importance of storage temperatures in maintaining flavor and quality of mandarins. Postharvest Biology and Technology, 64, 175-182.

Todisco, K. M., Clemente, E., \& Rosa, C. I. L. F. (2012). Conservação e qualidade pós-colheita de laranjas 'Folha Murcha' armazenadas em duas temperaturas. Revista em Agronegócios e Meio Ambiente, 5, 579-591.

Valencia-Chamorro, S. A., Pérez-gago, M. B., Del Río, M. A., \& Palou, L. (2010). Effect of antifungal hydroxypropyl methylcellulose-lipid edible composite coatings on penicillium decay development and postharvest quality of cold-stored "Ortanique" mandarins. Journal of Food Science, 75, 418-426.

Recebido: Novembro 12, 2018

Aceito: Junho 12, 2019

Como Citar: Veiga, J. C., Barbará, M. A., Silva, B. M. P., Valentini, S. R. T., Cristofani-Yaly, M., \& Bron, I. U. (2019). Refrigeração e cera na conservação pós-colheita da tangerina IAC 2019Maria. Citrus Research \& Technology, 40, e1046. https://doi.org/10.4322/crt.17219 